\title{
O reconhecimento pessoal e a psicologia judiciária: falibilidade do testemunho como reforço do etiquetamento e violação ao in dubio pro reo
}

Eyewitness identification and legal psychology: fallibility of the testimony as a reinforcement of the Labeling Approach and violation of in dubio pro reo

Marina Trindade Magalhães ${ }^{1}$

Instituto Brasiliense de Direito Público - Brasília/DF, Brasil mtrindade.marina@gmail.com

http://lattes.cnpq.br/1267722569654905

http://orcid.org/0000-0002-4638-9096

\begin{abstract}
RESUMO: O presente trabalho aborda o tema do reconhecimento pessoal no Brasil e nos Estados Unidos, bem como o estudo da psicologia judiciária relacionada ao testemunho. $O$ objetivo desta pesquisa é entender qual é o tratamento dado à colheita da prova testemunhal no Brasil? E nos Estados Unidos? Quais são os fatores que influenciam na falibilidade do testemunho? Por fim, a inobservância dos requisitos do art. 226 do Código de Processo Penal representa reforço à Teoria do Etiquetamento e à seletividade penal? Como metodologia, adotouse a revisão bibliográfica sobre o tema e a análise de alguns acórdãos exemplificativos sobre o assunto. $O$ trabalho visou analisar a literatura, nacional e norte-americana, sobre o reconhecimento pessoal; examinar o entendimento jurisprudencial acerca do tema; abordar variados fatores que podem influenciar no ato do reconhecimento pessoal; e, por fim, debater sobre a seletividade penal, que pode ser reforçada pela inobservância dos critérios legais para o reconhecimento pessoal. Conclui-se que, embora careça de atualizações, o art. 226 do Código
\end{abstract}

1 Especialista em Direito Penal e Processo Penal pelo Instituto Brasiliense de Direito Público - IDP. Bacharela em Direito pela Universidade de Brasília - UnB. Advogada. 
de Processo Penal deveria ser respeitado em sua integralidade, de modo a evitar a influência de fatores, como as falsas memórias e as problemáticas que envolvem o reconhecimento cross-racial, o weapon effect, dentre outros. Com respeito à legislação, aliado a técnicas adequadas de entrevista testemunhal, evita-se, assim, o fortalecimento da seletividade penal e da Teoria do Etiquetamento.

Palavras-chave: Reconhecimento pessoal; Reconhecimento fotográfico; Psicologia judiciária; Etiquetamento social.

ABSTRACT: The present article addresses aspects of eyewitness identification in Brazil and the United States, as well as some of the factors that imply the fallibility of testimony. The main purpose of the research is to understand how does each, Brazil and the United States, treat testimonial evidence? What are some of the factors the influence the fallibility of the testimony? Finally, does the non-observance of the legal criteria in the article 226 of the Brazilian Criminal Procedure Code reinforce the Labeling Approach and criminal selectivity? The methodology applied in the research consists in literature review and the analysis of some judicial cases in which eyewitness identification was used as evidence. The specific goals of the study were to analyze the Brazilian and North American doctrinal understanding of eyewitness identification; examine how the Brazilian courts addresses the issue; research the various factors that may influence the identification; and, finally, discuss about the criminal selectivity that can be reinforced by the non-observance of the legal criteria for eyewitness identification. One can conclude that the article 226 of the Criminal Procedure Code, even though it lacks some update, should be applied in its entirety in order to avoid the influence of factors such as false memories and issues involving cross racial identification, weapon effect, among others. Respecting legal criteria is also capable to avoid the strengthening of criminal selectivity and the Labeling Approach.

Keywords: Eyewitness identification; Photo identification; Criminal psychology: Labeling approach.

SUMÁRIO: Introdução; 1 Reconhecimento pessoal: posições doutrinárias e jurisprudenciais sobre o tema; 1.1 Reconhecimento pessoal no Brasil; 1.2 Reconhecimento pessoal nos Estados Unidos; 2 A psicologia judiciária e a prova testemunhal: fatores que influenciam na falibilidade do testemunho; 3 Teoria do Etiquetamento e o in dubio pro reo; Considerações finais; Referências. 


\section{INTRODUÇÃO}

O reconhecimento configura-se como um meio de prova no qual alguém identifica uma pessoa ou uma coisa que lhe é mostrada, como algo que já se tenha visto, perante a autoridade policial ou judiciária, nos moldes previstos em lei (LIMA, 2016, p. 703). No Brasil, o reconhecimento pessoal deve atender aos requisitos do art. 226 do Código de Processo Penal, de forma a evitar que procedimentos inadequados resultem em provas utilizadas no curso da ação penal. Na prática, no entanto, as disposições do citado artigo são tidas como sugestões, e não obrigatoriedades, de modo que grande parte dos reconhecimentos realizados na fase extrajudicial e em juízo é feita de maneira informal, em nome do princípio do livre convencimento motivado (LOPES JR., 2014, p. 494).

Nessa informalidade, reside a problemática do reconhecimento no ordenamento jurídico pátrio. Os incisos do art. 226 do Código de Processo Penal visam a uma maior garantia de fidelidade da prova que se pretende obter (LOPES JR., 2014, p. 495), o que diminui o efeito de fatores externos, como as falsas memórias, a influência da Teoria do Etiquetamento, o decurso de tempo entre o fato e o reconhecimento, dentre outros.

A inobservância dos procedimentos adequados pode ocasionar reconhecimentos deficientes e pouco confiáveis, o que resulta em decisões judiciais que reforçam a Teoria do Etiquetamento, trabalhada por autores, como Howard Becker, e, consequentemente, violam o in dubio pro reo, princípio que deveria ser aplicado em casos de razoável dúvida.

Em razão do exposto, torna-se imperiosa a necessidade de encontrar meios de fortalecer as técnicas aplicadas no ato de reconhecimento, de modo a aumentar a precisão e minimizar a falibilidade do testemunho (MALPASS et al., 1981, p. 343).

Dessa forma, orienta-se a pesquisa a partir das seguintes questões: como é realizada a colheita da prova testemunhal no Brasil? E nos Estados Unidos? Quais são os fatores que influenciam na falibilidade do testemunho? Atentando-se a isso, a inobservância dos requisitos do art. 226 do Código de Processo Penal leva ao reforço da Teoria do Etiquetamento e da seletividade penal? Para tanto, no primeiro capítulo, serão analisadas a doutrina jurídica e a jurisprudência que versam sobre o 
reconhecimento pessoal, de modo a trazer para a discussão diferentes visões sobre o art. 226 do Código de Processo Penal e a percepção das problemáticas que envolvem sua relativização. Será feita, ainda, a análise de casos e de estudos estrangeiros sobre o tema e a evolução da discussão nos Estados Unidos.

O segundo capítulo será destinado ao estudo de trabalhos que tratam da psicologia judiciária, no tocante às teorias que envolvem o reconhecimento pessoal, de modo a compreender os institutos psicológicos e os variados elementos que influenciam a construção da memória.

No terceiro e último capítulo, utilizando as lições extraídas do segundo capítulo, será abordada a Teoria do Etiquetamento, para analisar a forma como as concepções sociais influenciam os reconhecimentos fotográficos e pessoais, o que leva a uma seletividade no sistema penal. Por fim, analisar-se-á a adequação do art. 226 do Código de Processo Penal frente às problemáticas trabalhadas no texto.

\section{RECONHECIMENTO PESSOAL: POSIÇÕES DOUTRINÁRIAS E JURISPRUDENCIAIS SOBRE O TEMA}

O presente tópico do trabalho tem como objetivo abordar os principais aspectos sobre o reconhecimento pessoal no Brasil, sob a ótica da doutrina e da jurisprudência, e nos Estados Unidos, de modo a permitir um cotejo entre as diferenças e semelhanças relativas ao tratamento dado em cada país.

\subsection{RECONHECIMENTO PESSOAL NO BRASIL}

A prova testemunhal é o meio de prova mais utilizado no processo penal brasileiro (LOPES JR., 2014, p. 473). Por meio de prova são entendidas as atividades endoprocessuais, produzidas sob o crivo do contraditório e da ampla defesa, diferentemente dos meios de investigação, que representam as atividades, em regra, executadas nas fases preliminares de investigação (LIMA, 2016, p. 580).

Nesse passo, embora o Código de Processo Penal afirme que todas as provas são relativas e que nenhuma delas terá mais valor que a outra, 
na prática, a prova testemunhal exerce preponderante influência sobre as demais provas, principalmente quando a infração não deixa vestígios, sendo a palavra da vítima uma das únicas provas colhidas (LOPES JR.; GESU, 2007, p. 107).

Assim, ainda que seja possível recolher indícios que levam ao reconhecimento e à autoria em sede de investigação preliminar, é preciso que, em juízo, tais elementos sejam filtrados, à luz dos princípios do processo penal, a fim de que sejam utilizados em fundamentos de decisão e sentença (FRANÇA, 2012, p. 57).

No bojo das provas testemunhais - provas que dependem da memória das testemunhas - está o reconhecimento pessoal. Configurando uma das principais e mais frequentes diligências instrutórias no Brasil, o reconhecimento pessoal é regido pelas disposições do art. 226 do Código de Processo Penal (CPP) ${ }^{2}$, as quais indicam uma série de critérios que deveriam ser atendidos, a fim de dar credibilidade à palavra da testemunha, sem ofender princípios constitucionais, como o da presunção de inocência. A jurisprudência atual e dominante do Superior Tribunal de Justiça (STJ) e do Supremo Tribunal Federal (STF), entretanto, considera as disposições do art. 226 como meras sugestões, o que faz com que a não observância delas não implique em nulidade ${ }^{3}$.

22 “Art. 226. Quando houver necessidade de fazer-se o reconhecimento de pessoa, proceder-se-á pela seguinte forma: I - a pessoa que tiver de fazer o reconhecimento será convidada a descrever a pessoa que deva ser reconhecida; Il - a pessoa, cujo reconhecimento se pretender, será colocada, se possível, ao lado de outras que com ela tiverem qualquer semelhança, convidando-se quem tiver de fazer o reconhecimento a apontá-la; III - se houver razão para recear que a pessoa chamada para o reconhecimento, por efeito de intimidação ou outra influência, não diga a verdade em face da pessoa que deve ser reconhecida, a autoridade providenciará para que esta não veja aquela; IV - do ato de reconhecimento lavrar-se-á auto pormenorizado, subscrito pela autoridade, pela pessoa chamada para proceder ao reconhecimento e por duas testemunhas presenciais. Parágrafo único. O disposto no $\mathrm{n}^{\circ}$ III deste artigo não terá aplicação na fase da instrução criminal ou em plenário de julgamento."

3 Indica-se, a título de exemplo, os julgados: STJ, AgRg no AREsp 1617926/ SP, Rel. Ministro Nefi Cordeiro, Sexta Turma, julgado em 05/03/2020; STJ, AgRg no REsp 1827892/MG, Rel. Ministro Reynaldo Soares Da Fonseca, Quinta Turma, julgado em 18/02/2020; STJ, AgRg no AREsp 1534916/SP, Rel. Ministra Laurita Vaz, Sexta Turma, julgado em 06/02/2020; STJ, AgRg 
O Tribunal de Justiça do Distrito Federal e Territórios corrobora o entendimento sedimentado pelos Tribunais superiores e permite que os reconhecimentos no Distrito Federal sejam realizados sem atenção aos requisitos descritos no art. 226 do CPP, considerando os critérios do

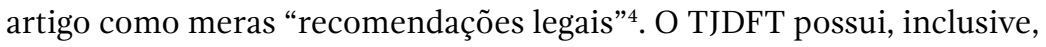
uma Jurisprudência em Temas sobre o assunto ${ }^{5}$ :

O art. 226 do Código de Processo Penal prevê recomendações quanto ao reconhecimento de pessoas, e não exigências legais. A inobservância das formalidades previstas nesse artigo, portanto, não invalida o reconhecimento do réu, especialmente quando estiver amparado por outros elementos de prova.

Percebe-se, com esse entendimento, uma grande ofensa aos princípios norteadores do Processo Penal ao admitir-se uma prova que não atenda aos requisitos impostos em lei. As autoridades policiais ou judiciais, ao questionar se a vítima ou a testemunha reconhece o acusado como o autor do delito, sem colocá-lo próximo a outras pessoas com características semelhantes (art. 226, II) ou até mesmo sem proceder a uma prévia colheita de informações sobre o suposto autor do delito (art. 226, I), infringem a norma processual penal e permitem que reconhecimentos frágeis resultem em condenações.

Sobre o tema, Lopes Jr. (2014, p. 494) é firme em defender que:

O ponto de estrangulamento é o nível de (in)observância por parte dos juízes e delegados da forma prevista no Código de Processo

no REsp 1808455/SP, Rel. Ministro Joel Ilan Paciornik, Quinta Turma, julgado em 12/11/2019; STJ, AgRg no HC 539.979/SP, Rel. Ministro Jorge Mussi, Quinta Turma, julgado em 05/11/2019; STF, RHC 125026 AgR, Rel. Ministra Rosa Weber, Primeira Turma, julgado em 23/06/2015; STF, RHC 119439, Rel. Ministro Gilmar Mendes, Segunda Turma, julgado em 25/02/2014,

4 A título de exemplo, cita-se o Acórdão 1205752, 20180810034499APR, Rel. Desembargador Waldir Leôncio Lopes Júnior, $3^{\mathrm{a}}$ Turma Criminal, data de julgamento: 3/10/2019.

5 Reconhecimento pessoal realizado de forma diversa da prevista no CPP - validade. Disponível em: <https://www.tjdft.jus.br/consultas/jurisprudencia/ jurisprudencia-em-temas/jurisprudencia-reiterada-1/direito-processual-penal/reconhecimento-realizado-de-forma-diversa-da-prevista-no-cpp-validade> Acesso em: nov. 2019. 
Penal. (...) Trata-se de uma prova cuja forma de produção está estritamente definida e, partindo da premissa de que - em matéria processual penal - forma é garantia, não há espaço para informalidades judiciais. Infelizmente, prática bastante comum na praxe forense consiste em fazer "reconhecimentos informais", admitidos em nome do princípio do livre convencimento motivado.

Cumpre frisar que a atenção aos incisos do art. 226 fornece à prova coletada maior segurança. Ao solicitar que a testemunha/vítima descreva a pessoa que deve ser reconhecida, o processo fragmentário da memória torna-se conhecido, o que possibilita ao juiz perceber se o declarante tem a mínima lembrança da pessoa a ser reconhecida (NUCCI, 2015, p. 439).

Ato contínuo, ao colocar a pessoa que se pretende reconhecer ao lado de outros indivíduos com características semelhantes, a vítima/ testemunha é levada, diante da dúvida, a exercer o processo de comparação, para buscar a real imagem daquele que deva ser reconhecido (ibid, 2015, p. 439).

A forma como as perguntas são formuladas pela autoridade policial também possui o condão de influenciar no testemunho. O modo e o contexto de uma pergunta podem sugestionar a resposta da vítima ou da testemunha (TORTORA, 2013, p. 1523). No Brasil, há uma predominância de perguntas fechadas, com carga de sugestionabilidade, aptas a interferir na qualidade do testemunho (STEIN; ÁVILA, 2018, p. 48).

Outro exemplo de procedimento apto a estigmatizar e influenciar no reconhecimento é o que, nos Estados Unidos, é chamado de show-up. Neste, a autoridade policial conduz uma testemunha ou vítima a um local para mostrar a ela apenas um suspeito que já tenha sido detido. Essa técnica tem alto grau de induzimento, visto que o uso de algemas, ou o fato de estar dentro do camburão, leva a vítima a crer que a polícia tem mais elementos para acreditar que aquele é o culpado. Em razão da possível sugestionabilidade que esse procedimento pode acarretar nos testemunhos, muitas cortes de justiça americanas já proibiram tal prática ${ }^{6}$.

6 CALIFORNIA INNOCENCE PROJECT. Eyewitness Identification. Disponível em: <https://californiainnocenceproject.org/issues-we-face/eyewitness-identification/>. Acesso em: nov. 2019. 
Exemplo é a Suprema Corte do estado de Wisconsin, nos Estados Unidos, a qual determinou que prova obtida por meio de um reconhecimento com base no show-up é inerentemente sugestiva e não será admitida, salvo se, considerando todas as circunstâncias, a utilização dela fosse estritamente necessária (NORTON, 2006, p. 1).

No Brasil, uma pesquisa realizada pelo IPEA (Instituto de Pesquisa Econômica Aplicada) mostrou que a técnica show-up, valendo-se de uma variedade de práticas de reconhecimento, foi a estratégia predominante nos reconhecimentos realizados em 2014 e 2015. Somado a isso, foi identificada a média de um ano entre o fato delituoso e a coleta de provas testemunhais em juízo, tempo excessivo, quando se considera o natural processo de esquecimento, o qual sofre interferências internas e externas, à medida que o tempo passa (STEIN; ÁVILA, 2018, p. 47-48).

Sobre a questão do decurso de tempo entre o fato delituoso e a coleta de provas testemunhais, estudos mostram que não apenas o tempo decorrido tem efeito sobre a memória, mas também os aspectos ambientais do local do crime, como a iluminação, e o próprio tempo de exposição da vítima ao acusado influenciam a recordação dos fatos (HANDBERG, 1995, p. 1053).

No mesmo problema recai o reconhecimento fotográfico, prova inominada amplamente utilizada nos procedimentos de reconhecimento (LIMA, 2016, p. 704). Para Guilherme Nucci (2015, p. 438), devido à probabilidade de erros, o reconhecimento fotográfico deve seguir as disposições dos incisos do art. 226 do Código de Processo Penal, bem como deve ser considerado uma prova indireta, um mero indício. A jurisprudência do STJ, nessa esteira, é clara ao afirmar que sua utilização é possível, desde que corroborada por outros elementos de prova ${ }^{7}$, contudo, não raro, o reconhecimento fotográfico é a única prova a embasar a sentença condenatória.

O reconhecimento fotográfico deve servir como ato preparatório ao reconhecimento pessoal sem, entretanto, desconsiderar as formalidades

7 Indica-se os seguintes julgados: STJ, HC 461.634/SP, Rel. Ministra Laurita Vaz, Sexta Turma, julgado em 08/11/2018; STJ, AgRg no HC 462.030/SP, Rel. Ministro Ribeiro Dantas, Quinta Turma, julgado em 05/03/2020; STJ, AgRg no AgRg no AREsp 1585502/SP, Rel. Ministro Joel Ilan Paciornik, Quinta Turma, julgado em 06/02/2020. 
devidas, para que não se contamine o reconhecimento realizado pela vítima. As provas testemunhais, bem como os reconhecimentos, são altamente suscetíveis a mentiras e à influência das falsas memórias. Logo, a valoração probatória delas deve levar em consideração a variável complexa que é a memória (LOPES JR., 2014, p. 497).

O reconhecimento por foto deve ocorrer nos casos em que o suspeito não tenha sido preso - situação em que se deve proceder ao reconhecimento pessoal - e deve ser feito de modo não sugestionável, com fotografias do mesmo tamanho e coloridas (BESSNER, 1983, p. 334).

Na XX Jornadas Ibero-Americanas de Direito Processual Penal, realizadas em 2006, na Espanha, discutiu-se o caso brasileiro e concluiu-se que o problema reside no descumprimento do rito previsto para a coleta de provas, o que resulta em um reconhecimento fotográfico precário (FRANÇA, 2012, p. 59).

Cecconello et al (2018, p. 1063) destaca que os profissionais que atuam nos procedimentos de reconhecimento não são capacitados cientificamente para tal, o que acarreta em oitivas conduzidas com base na própria experiência. Somado a isso, há o tempo decorrido entre o fato e a entrevista e a possibilidade de repetição da prova.

No tocante à repetição das provas, os autores sustentam que o número de vezes em que a vítima ou testemunha é entrevistada, aliado à ausência de procedimentos adequados, aumenta a chance de a memória original ser modificada, com a perda e distorções das informações (CECCONELLO et al, 2018, p. 1063):

Se a vítima identifica o suspeito como perpetrador do ato, esse rosto torna-se atrelado à memória do evento. Assim, a repetição do reconhecimento de um suspeito não resulta em nenhum benefício: uma vez que um suspeito é reconhecido (seja ele inocente ou não), há maior probabilidade que esse mesmo rosto seja identificado em um novo reconhecimento subsequente. Além disto, o procedimento de repetição do reconhecimento de um suspeito pode ter o efeito indesejado de gerar uma maior familiaridade com esse rosto, levando a testemunha a ter, ainda, maior convicção de que está diante do real perpetrador, mesmo que ele não seja. Após múltiplos reconhecimentos, a confiança da testemunha não é resultante da memória original do fato, mas sim da repetição à exposição 
do rosto do suspeito, o que pode levar um suspeito inocente a ser reconhecido com alto grau de certeza.

Os americanos chamam o problema relativo à repetição dos reconhecimentos de mugshot commitment. Outro processo mental cognitivo que afeta o reconhecimento, quando realizado mais de uma vez, é o mugshot exposure. Este acontece quando a testemunha não identifica nenhum suspeito no primeiro reconhecimento fotográfico realizado, mas depois, em outro procedimento de reconhecimento, indica um dos suspeitos que estava presente no primeiro, o que aumenta a probabilidade de um reconhecimento errôneo (DOTSON, 2014, p. 799).

Assim, importa considerar a função (re) cognitiva da persecução penal - partindo de provas, trabalha-se com fatos passados, para que se possa elaborar uma história sobre o crime (GESU, 2014, p. 43) -, de modo a conferir maior controle sobre a prova, assegurando o regime processual democrático, por meio da limitação do poder e da legalidade do ato. Deve o Estado, portanto, impor às suas decisões uma sustentação por meio de elementos empíricos válidos e obtidos de maneira objetiva e racional, a fim de superar o nível de dúvida razoável que, em nosso ordenamento, milita em favor do acusado.

\section{2 RECONHECIMENTO PESSOAL NOS ESTADOS UNIDOS}

Nos Estados Unidos, a maioria das cortes judiciais utiliza os critérios definidos pela Suprema Corte, no caso Manson vs. Brathwaite, em 1977, para avaliar se os reconhecimentos pessoais são confiáveis para serem apresentados ao júri (TRENARY, 2013, p. 1257). São cinco fatores que devem ser levados em consideração: (i) a chance que a testemunha teve de ver o acusado no momento do crime; (ii) o grau de atenção da testemunha; (iii) a precisão da prévia descrição da testemunha em relação ao acusado; (iv) o grau de certeza demonstrado pela testemunha no momento do reconhecimento; e (v) o tempo decorrido entre o crime e o reconhecimento (RABNER, 2012, p. 1253).

Smalarz e Wells (2012, p. 20) ponderam, no entanto, que, à época do caso Manson vs. Brathwaite, não havia literatura específica sobre o tema do reconhecimento pessoal. Assim, esses critérios foram estabelecidos 
pautados no senso comum da Corte e não são aptos, isoladamente, a definir o grau de confiabilidade do testemunho, principalmente quando envolvidos procedimentos sugestivos na coleta das provas.

Devido a isso, é importante aliar os critérios do caso Manson a outras práticas. Nesse sentido, o Codes of Practice determina que, antes de submeter a testemunha/vítima a um reconhecimento pessoal ou fotográfico, é preciso colher a descrição dela em relação ao acusado (como um retrato falado). Só após essa primeira descrição feita pela vítima é que o policial pode levá-la a um reconhecimento pessoal sem, contudo, chamar a atenção dela para algum indivíduo em particular, a fim de evitar, assim, influenciar no reconhecimento (ROBERTS, 1999, p. 251-252).

Assim como no Brasil, a importância dada ao reconhecimento pessoal nos Estados Unidos é grande. Estudos indicam que os jurados americanos creditam muita segurança nas provas testemunhais e nos reconhecimentos pessoais $^{8}$ (MAYER, 1994, p. 818-819). Em uma pesquisa realizada em 2009 pela CBS News, apenas 7\% dos americanos entrevistados acreditavam que o reconhecimento pessoal era falho, já em 2011, 37\% dos cidadãos americanos afirmaram que a declaração isolada de uma testemunha é suficiente para condenar alguém por um crime (ROSE; BECK, 2014, p. 1). Por essa razão, especialistas chamam a atenção da polícia e do judiciário americano à falibilidade dos reconhecimentos pessoais, de modo a assegurar um processo criminal justo (WALSH, 2013, p. 1416).

Uma pesquisa realizada pelo Innocence Project ${ }^{9}$ mostrou que erros no reconhecimento pessoal são as maiores causas de condenações errôneas no país, onde mais de 70\% das condenações foram revisadas após o teste de DNA (NAUDÉ, 2015, p. 188). Outra pesquisa indica que, em um universo de 261 casos de absolvição após uma condenação

8 "As Justice Brennan stated in his dissent in Watkins v. Sowders: '[E]yewitness identification evidence has a powerful impact on juries. Juries seem most receptive do, and not inclined to discredit, testimony of a witness who states that he saw the defendant commit the crime""

9 O Innocence Project foi criado em 1992, por Peter Neufeld e Barry Scheck, na Cardozo School of Law e tem como objetivo reverter condenações errôneas por meio do teste de DNA e, com isso, reformar o sistema de justiça criminal, de modo a prevenir maiores injustiças. 
indevida, $75 \%$ foram condenações resultantes, no todo ou em parte, de um reconhecimento pessoal falho (CLARK, 2010, p. 1106).

Quanto ao reconhecimento fotográfico, à semelhança do que ocorre com o reconhecimento pessoal, é recomendado que seja mostrado às testemunhas um acervo de, no mínimo, cinco fotos de indivíduos diferentes (sendo quatro de indivíduos sem qualquer relação com o crime), com características semelhantes às do acusado, feita a advertência, contudo, de que é possível o acusado não estar representado nas fotos. Esse procedimento evita a ocorrência de reconhecimentos falhos e sugestionáveis (CONWAY, 2015, p. 81-82), uma vez que a testemunha vai querer identificar alguém entre as fotos demonstradas e, assim, tenderá a indicar aquele que mais se pareça com o suspeito, em vez de falar que não reconhece ninguém (WELLS et al., 1998, p. 613-614). Para isso, nos Estados Unidos, assim como no Reino Unido, existem bibliotecas digitais de faces para line-ups, as quais possibilitam a escolha rápida de indivíduos com feições semelhantes às do suspeito (CECCONELLO; STEIN, 2020, p. 180).

Esse último aspecto evidencia uma grande diferença entre o reconhecimento fotográfico realizado nos Estados Unidos e o realizado no Brasil. Enquanto o primeiro conta com um acervo digital de fotos, no Brasil, esse acervo, mesmo quando digital, é composto por fotografias retiradas de bancos de dado policiais e, às vezes, até mesmo de redes sociais, consideradas "fontes abertas" de investigação (FRANÇA, 2012, p. 72).

Outro ponto relevante refere-se à indicação de que os policiais responsáveis pela condução da sessão de reconhecimento não tenham conhecimento de quem é o autor do delito, para que não ocorra qualquer tipo de interferência - voluntária ou involuntária - no reconhecimento realizado pela testemunha ou vítima (FRANÇA, 2012, p. 64). O agente que tenha conhecimento de quem é o suspeito pode ter expectativas quanto ao reconhecimento e gerar estímulos inconscientes, que poderão ser captados pela vítima, que tenderá a querer suprir a expectativa do agente (DOTSON, 2014, p. 796). Os americanos chamam essa condução do reconhecimento de double-blind procedure ${ }^{10}$ (BROWN; SALOOM, 2013, p. 541).

10 A tradução seria algo como "procedimento de cegueira mútua". 
Uma vez possibilitada a double-blind procedure, recomenda-se que a apresentação dos indivíduos para reconhecimento seja feita de forma individual, de modo que a vítima ou testemunha tenha de olhar para um indivíduo de cada vez. Essa técnica aumenta a precisão dos reconhecimentos e deve ser utilizada apenas quando o agente também não souber quem é o suspeito (BROWN; SALOOM, 2013, p. 541).

É imperioso, ainda, que o line-up - a apresentação dos indivíduos para o reconhecimento - seja feito de modo não sugestivo, sem chamar atenção para uma pessoa em específico. Assim, deve-se apresentar à vítima/testemunha indivíduos com características semelhantes entre si e que se enquadrem na descrição do acusado. Um line-up sugestivo aumenta drasticamente as chances de reconhecimentos equivocados (SMALARZ; WELLS, 2012, p. 16).

Há, nos Estados Unidos, ainda, uma linha de atuação que foca na parte judicial (trial) do processo. Como meio de evitar que reconhecimentos inadequados sejam utilizados para fundamentar decisões, a autoridade judicial deve usar o próprio poder para excluir do julgamento qualquer reconhecimento que seja considerado "fraco". Somado a isso, deve-se lançar mão do conhecimento de especialistas em testemunhos para instruir os jurados sobre os perigos do reconhecimento pessoal e dos fatores que podem comprometer a validade (LEVERICK, 2016, p. 561-562).

Desse modo, reconhecendo a falibilidade da prova testemunhal, o sistema de justiça dos Estados Unidos criou diversas linhas de atuação, para tentar resolver o problema. Nesse sentido, a Suprema Corte afirmou que a Quinta e a Sexta Emendas da Constituição dos Estados Unidos conferem ao acusado determinadas garantias contra procedimentos de reconhecimento sugestionáveis ${ }^{11}$.

É possível concluir que, assim como no Brasil, a prova testemunhal - em especial o reconhecimento pessoal e fotográfico - também representa um problema no sistema de justiça norte-americano. Tal realidade se dá devido ao fato de que testemunhas e vítimas, enquanto seres

11 SHEEHAN, Christian. Making the jurors the experts: the case for eyewitness identification jury instructions. Boston College Law Review, Newton Centre, v. 52, p. 653, 2011. 
humanos, são suscetíveis aos mesmos tipos de influência e de falibilidade em qualquer parte do mundo.

A diferença reside, contudo, no tratamento dado em cada país. Enquanto, no Brasil, a jurisprudência diverge de uma boa parte da doutrina e aceita a "informalidade" no ato do reconhecimento, nos Estados Unidos, gradualmente, passou-se a adotar medidas que visam à produção de provas de forma mais confiável, o que diminui a interferência de fatores que lesam o reconhecimento, os quais serão analisados no próximo tópico.

\section{A PSICOLOGIA JUDICIÁRIA E A PROVA TESTEMUNHAL: FATORES QUE INFLUENCIAM NA FALIBILIDADE DO TESTEMUNHO}

Neste tópico, serão abordados os fatores que influenciam a qualidade do reconhecimento pessoal e fotográfico, os quais interferem na qualidade e na confiabilidade da prova coletada nas fases investigativa e judicial.

Compreender os fenômenos que envolvem a memória se faz importante para o processo penal, visto que, no processo, por meio de uma atividade recognitiva, faz-se uma retrospectiva do passado. Essa retrospectiva é impulsionada pelas partes, que se utilizam das provas para reconstruir, no presente, o delito ocorrido no passado (GESU, 2014, p. 130). Uma das maiores barreiras que essa reconstrução enfrenta são as chamadas falsas memórias.

Damásio (1994, p. 128-129) pontua que imagens, pessoas, palavras e frases com as quais nos deparamos durante nossa vida não são armazenadas em nossa memória em forma de fotografias, e sim como "reconstruções momentâneas, tentativas de réplica, de padrões que já foram experienciados, nas quais a probabilidade de se obter uma réplica exata é baixa (...)".

As falsas memórias resultam da sugestionabilidade da memória, representam a incorporação e a recordação de informações falsas que o indivíduo lembra como sendo verdadeiras (STEIN, 2010, p. 23). As falsas memórias podem ser classificadas em espontâneas e sugeridas. $\mathrm{O}$ primeiro tipo resulta de distorções endógenas (autossugeridas), as quais são frutos do próprio funcionamento da memória. As falsas memórias sugeridas, por sua vez, são provenientes da sugestão de falsa informação 
externa ao sujeito e posterior ao evento ocorrido, a qual passa a incorporar a memória original (ibid, 2010, p. 25).

No mesmo sentido, Elizabeth Loftus (1976, p. 97) constatou, por meio de pesquisas, que a memória é formada por múltiplas fontes, desde a percepção original do evento até informações e conhecimentos adquiridos antes e após o fato. É possível concluir, dessa maneira, que a informação errônea possui a capacidade de se incorporar às nossas lembranças quando falamos com outras pessoas, quando somos interrogados de maneira evocativa e até quando nos é mostrada uma reportagem sobre um evento que nós mesmos vivemos.

A tendência humana, diante de um delito, é a de guardar apenas a emoção do momento e deixar no esquecimento a memória cognitiva, responsável pelos detalhes técnicos e despida de contaminação (emocional, subjetiva) (LOPES JR.; GESU, 2008, p. 102). Estudos indicam que, apesar de termos mais facilidade de recordar eventos emocionais, essa lembrança também pode vir acompanhada de falsas memórias, ou seja, o fato de lembrarmos mais não significa que tais lembranças estejam imunes à distorção (STEIN et al, 2010, p. 88).

Desse modo, sobre a ocorrência de falsas memórias no processo penal, Cristina Di Gesu (2014, p. 312) defende que um dos grandes problemas da prova reside na contaminação da reconstrução de fatos passados, diretamente relacionada ao modo de colheita da prova. A percepção de determinado evento está eivada de interpretações subjetivas, e, ao tentar recuperar os fragmentos da memória, utilizamos mecanismos disponíveis que, por sua vez, podem ser imaginados, reais e até mesmo sugestionáveis.

Um recorrente exemplo de sugestionabilidade é a influência da mídia. O cenário imposto pela mídia, por meio de matérias veiculadas na televisão, pode confundir a testemunha sobre aquilo que ela, de fato, presenciou no momento do delito com o que leu ou ouviu posteriormente (GESU, 2014, p. 186). Nota-se que o discurso da criminologia midiática, embora seja, muitas vezes, "equivocado, punitivista e seletivo" (DIAS et al, 2013, p. 396), é aceito com facilidade pela população, que enxerga na punição "exemplar" a solução para a criminalidade na sociedade.

A doutrina trabalha com muitos exemplos nos quais a falsa memória influenciou atos de reconhecimento e testemunho judiciais. Um interessante caso a ser citado é o do norte-americano Unabomber. 
Terrorista conhecido por enviar, via postal, bombas a universidades e a departamentos nos Estados Unidos, Ted Kaczynski foi flagrado por uma mulher que sobreviveu a um de seus atentados. Ao fornecer detalhes sobre a aparência dele para um artista de retrato falado, a testemunha descreveu determinadas fisionomias, de fato muito parecidas com as de Kaczynski. Anos depois, no entanto, ao ser chamada para realizar um novo retrato falado, a mulher, inconscientemente, descreveu características diferentes da do primeiro retrato falado e, coincidentemente, muito semelhantes às do artista responsável pelo primeiro retrato falado ${ }^{12}$.

O supracitado exemplo enquadra-se muito bem no caso da sugestionabilidade, definido como a sugestão de informações falsas apresentadas a sujeitos, deliberadamente ou não, passando a integrar parte da experiência real vivenciada (STEIN et al, 2010, p. 167), resultando, destarte, na fragilidade do testemunho coletado.

Outro exemplo de sugestionabilidade refere-se a um procedimento adotado no Brasil, no qual se mostra um álbum de fotografias à vítima ou testemunha, antes que se realize um reconhecimento pessoal. A apresentação de um grande número de rostos sobrecarrega o processo cognitivo e reduz a capacidade de reconhecer corretamente o criminoso (CECCONELLO; STEIN, 2020, p. 177).

Quanto ao reconhecimento fotográfico, Cristina Di Gesu (2014, p. 133) defende:

A vítima ou testemunha certamente não identificará o imputado se não o conhece, já que a imagem deste não estará guardada em sua memória. Todavia, se for induzido por uma fotografia, no ato de reconhecimento propriamente dito, talvez se recorde não da pessoa envolvida no delito, mas sim daquela que lhe foi mostrada no álbum.

A literatura confirma o posicionamento da autora. Elizabeth Loftus (1976, p. 93) narra a história de um cobrador de trem, vítima de

12 GETZ, Dana. Who was the unabomber sketch artist? 'Manhunt Unabomber' claims there was more than one. Disponivel em: <https://www.bustle.com/p/ who-was-the-unabomber-sketch-artist-manhunt-unabomber-claims-therewas-more-than-one-78167>. Acesso em: maio 2018. 
um crime com arma de fogo. No momento do reconhecimento, a vítima indicou um marinheiro como o culpado pelo delito. O marinheiro, no entanto, tinha um álibi seguro e foi solto. Ao questionar a vítima sobre o reconhecimento falho que havia feito, ela afirmou que o marinheiro lhe parecia familiar e, por essa razão, indicou ele como o suspeito. Ocorre que, a base de trabalho do marinheiro era próxima à estação de trem e ele havia, em outras três ocasiões, comprado passagens com a vítima. Trata-se do fenômeno chamado de unconscious transference ${ }^{13}$.

Soma-se a isso o fato de que as pessoas costumam ter dificuldade em diferenciar indivíduos de grupos étnicos diferentes do seu, ou seja, pessoas brancas teriam menos facilidade em reconhecer um indivíduo negro específico quando este estivesse inserido em um grupo composto por apenas pessoas negras, do mesmo gênero ${ }^{14}$. Estudos indicam que, embora ocorram erros em reconhecimentos entre indivíduos da mesma raça (uma pessoa branca reconhecendo outra pessoa branca, ou uma pessoa negra reconhecendo outra pessoa negra), a margem de erro é muito maior quando se trata de reconhecimentos entre pessoas de raças diferentes (cross-racial) (GEE, 2009, p. 100).

Sobre o tema, pesquisas sobre o chamado Other Race Effect (ORE) indicam que a falta de contato inter-racial resulta em indivíduos que desenvolvem mais capacidade de distinção e reconhecimento entre indivíduos da mesma etnia (HUGENBERG et al, 2010, p. 5). Há dados que indicam que pelo menos $49 \%$ das condenações errôneas envolveram um reconhecimento cross-racial. Estudos descobriram que mais de dois terços dos reconhecimentos pessoais errados, em crimes sexuais, envolviam acusados negros e, desses, $72 \%$ eram com vítimas brancas (LEVERICK, 2016, p. 561).

Steblay (2015, p. 1104) sustenta que há, assim como a dificuldade de reconhecimento cross-racial, outros dois fatores que podem resultar em deficiências no procedimento de reconhecimento e que merecem atenção. O primeiro exemplo dado é o medo da testemunha ou vítima no

13 Transferência inconsciente, em tradução literal.

14 BENSON, Christopher. The problem with eyewitness identification. Disponível em: <http://www.chicagoreporter.com/problem-eyewitness-identification/>. Acesso em: nov. 2019. 
momento do delito. O temor é passível de diminuir a qualidade da memória, uma vez que o efeito fight or flight ${ }^{15}$, resposta fisiológica à ameaça, centra toda a energia e os esforços no objetivo de sobrevivência, e não no de retenção de memórias. Assim, como já citado, a emoção do evento permanece, mas os detalhes técnicos são perdidos (ibid, 2015, p. 1105).

Uma pesquisa feita por Tim Valentine e Jan Mesout (2009, p. 159) concluiu que o reconhecimento pessoal foi significativamente prejudicado pelo alto nível de stress da vítima/testemunha. Apenas 17\% dos indivíduos com a taxa de stress acima da média conseguiram identificar corretamente uma pessoa, no contexto de um álbum de fotografias com nove fotos diferentes. Já as pessoas que ficaram abaixo da média na escala do stress, 75\% foram capazes de indicar corretamente o "culpado".

O segundo exemplo trazido por Steblay (2015, p. 1105) é o chamado weapon focus effect. Basicamente, diz respeito ao efeito da arma no momento do crime, ou seja, a vítima voltará a atenção para a arma e deixará de lado as características físicas do autor do delito. Nesse ponto, pesquisas mostram que a presença da arma reduz a precisão dos reconhecimentos posteriores.

Outro fator que merece ser levado em consideração é o da coautoria ou participação. Um estudo realizado no Reino Unido, com 72 (setenta e dois) participantes, entre homens e mulheres, indicou que a testemunha ocular de um crime que envolva mais de um indivíduo tem dificuldades em diferenciá-los, uma vez que a memória tem origem comum (HOBSON; WILCOCK, 2011, p. 295). Isso não apenas dificulta o reconhecimento de cada um dos envolvidos, como também a indicação individualizada da participação de cada um.

Todos esses estudos que vêm sendo realizados sobre a memória e sobre a influência dela nos atos de reconhecimento levaram os pesquisadores a afirmar que as lembranças que possuímos sobre nosso passado não são um retrato fiel dos fatos (STEIN et al, 2010, p. 101).

Isso ocorre em razão do processo de formação da memória: a codificação. Todos os elementos a que a vítima é exposta durante o fato são interpretados pelo cérebro e podem vir a integrar a sua memória. A capacidade de atenção do ser humano, no entanto, é limitada, o que

15 Lutar ou fugir, em tradução literal. 
torna impossível a missão de codificar todos os estímulos que ocorrem no ambiente (CECCONELLO et al, 2018, p. 1060).

Desse modo, cresce a relevância de pesquisas no campo, assim como a adaptação dos procedimentos de reconhecimento, levando em considerações todos os fatores já abordados, que implicam na falibilidade do testemunho. Todo esse cuidado tem como objetivo a melhora do sistema de justiça criminal, de modo a evitar a violação a preceitos básicos, como o in dubio pro reo e o reforço à Teoria do Etiquetamento, conforme veremos no próximo capítulo.

\section{TEORIA DO ETIQUETAMENTO E O IN DUBIO PRO REO}

O estudo das falsas memórias e dos fatores que implicam no reconhecimento pessoal é essencial para se entender o seu efeito na seletividade penal que ocorre no Brasil. Essa seletividade reflete a relação social de poder, a qual encampa a noção de que a população marginalizada representa a "clientela" do sistema penal (MAZONI; FACHIN, 2012, p. 5).

O conceito de seletividade tem origem na Teoria do Labelling Approach, ou Etiquetamento. Para essa teoria, as relações sociais e de controle de poder influenciam a seleção das condutas a serem criminalizadas e a reação social destinada a cada uma delas; aqueles que transgredirem essas “normas" sociais são considerados outsiders ${ }^{16}$ (BECKER, 1997, p. 1).

A Teoria do Labelling Approach, afirmam Mazoni e Fachin (2012, p. 7), inaugura a chamada Criminologia Crítica, a qual pretende, com base no conflito de classes e de relações sociais, compreender a criminalização, enquanto relacionada aos processos de estratificação e de antagonismos estruturais.

Nesse passo, sociólogos perceberam que taxar alguém como "desviante" não é resultado automático do cometimento de um ato desviante. O que ocorre é que tal etiquetamento é resultado de uma interação entre o ator e a sociedade na qual se insere, o que permite que a mesma ação seja classificada como desviante quando cometida por um indivíduo e não classificada quando cometida por outro ator (MARSHALL; PURDY, 1972, p. 541).

16 Por outsiders, pode-se entender desviantes, marginalizados. 
Destarte, o Labelling Approach procura demonstrar a relevância da reação social para o delito. Em outras palavras, a forma como os rótulos e os estereótipos de uma sociedade influenciam as decisões dos órgãos do Judiciário em relação ao delito. Para Ávila (2013, p. 185), o delito é uma construção social, a qual exige uma ação e uma posterior reação social negativa; assim, o delinquente não é o que pratica um crime, mas aquele que recebe a etiqueta de delinquente.

A seletividade aqui definida tem reflexo na própria população carcerária. Em dezembro de 2019, mais de $62 \%$ da população prisional não possuía Ensino Médio e menos de 1\% tinha graduação (INFOPEN, 2019). O mesmo levantamento indica que cerca de $60 \%$ da população carcerária é composta por homens e mulheres de pele negra ou parda, contrastando com, aproximadamente, $28 \%$ de brancos e $0,7 \%$ de amarelos. Percebe-se, assim, que, das mais de 740.000 pessoas encarceradas em dezembro de 2019, a maioria pertence a classes menos favorecidas da sociedade, a julgar pelo nível de escolaridade.

Sobre essa predominância, Baratta (2003, p. 4) pontua que, embora os dados, geralmente, mostrem a prevalência de indivíduos dos estratos mais baixos da sociedade encarcerados, os comportamentos socialmente negativos não lhe são próprios. Os desvios ocorrem em todos os níveis da sociedade e "as violações mais graves aos direitos humanos ocorrem por obra de indivíduos pertencentes aos grupos dominantes (...)”.

No mesmo sentido, Zaffaroni (2013, p. 205) complementa que essa realidade demonstra como o sistema penal operacionaliza uma atuação seletiva, baseada nos estigmas já estabelecidos: homens, jovens, das classes mais carentes.

O aumento da população carcerária, assim, deve-se mais a uma política de repressão e de criminalização da pobreza do que a uma política apta a diminuir as ocorrências criminais (MONTEIRO; CARDOSO, 2013, p. 101).

Oscar Mellim Filho (2009, p. 95), nessa toada, conclui que o comportamento considerado criminoso, portanto, é fruto de uma construção social, de uma ação em desconformidade com as expectativas de determinado grupo social. Ao interpretar condutas, os aplicadores do direito e a sociedade criam o desvio e a etiqueta, com base em fatores, como a natureza do ato, suas circunstâncias, a classe social 
a que pertence o agente e o nível de tolerância em relação à conduta considerada infracional.

Ainda sobre a seletividade do sistema penal, cumpre trazer à baila a análise de Eugenio Raúl Zaffaroni (2013, p. 176), disposta em sua obra "A Questão Criminal”:

Desde a segunda metade do século passado, fica claro para a criminologia que o poder punitivo, com sua seletividade estrutural, criminaliza umas poucas pessoas e as usa para projetar-se como neutralizador da maldade social. Apresenta-se com o poder racional que encerra a irracionalidade em prisões e manicômios. Assim enfeitado, canaliza as pulsões de vingança, o que lhe proporciona uma formidável eficácia política, que não se aplica por circunstâncias conjunturais, pois se mantém inalterada ao longo da história do poder punitivo estatal e mesmo pré-estatal.

Percebe-se, assim, o fenômeno da criminalização primária. Trata-se do processo legislativo de criminalização de condutas e cominação de penas. Nesta, instrumentaliza-se o controle das classes menos favorecidas, tendo como referencial a manutenção do status quo das classes dominantes (MARTINI, 2007, p. 46).

Na criminalização primária, o sistema punitivo estatal elege condutas para rotular de criminosas, excluindo outros comportamentos, ainda que de maior periculosidade social. Essa escolha possui feição notadamente ideológica e traz para a regulação da vida social os valores e as concepções do legislador, em uma evidente seletividade, na qual, geralmente, se pune com maior rigor os delitos típicos das classes mais baixas (MOREIRA, 2010, p. 10).

Em um segundo momento, e de especial relevância para o presente estudo, tem-se a chamada criminalização secundária. Operada por todos os agentes públicos que participam da persecução penal, em qualquer das suas fases, tal criminalização ocorre "por meio de posturas desiguais, burocratizadas e estigmatizantes, reduzindo a capacidade de ação e de comunicação do suposto delinquente no ínterim do processo criminal" (MAZONI et al, 2012, p. 7). Trata-se da concretização do jus puniendi do Estado.

A criminalização secundária é a fase na qual o Direito Penal revela o caráter eminentemente seletivo. Para Baratta (2003, p. 4), o 
funcionamento da justiça penal está dirigido, quase exclusivamente, contra as classes mais baixas da sociedade. É no processo que se lida com as pessoas, "onde se enxergam seus olhos e peles (...), e onde as seletividades ganham chancela oficial in loco" (DIVAN, 2017, p. 22).

Exemplo dessa criminalização é o procedimento do reconhecimento fotográfico. As fotografias apresentadas à vítima/testemunha fazem parte do portfólio da autoridade policial, com imagens de indivíduos com maus antecedentes (GESU, 2014, p. 300). Esses álbuns de fotografias contam com fotos de suspeitos, de presos e de indiciados pelo delito cometido, divididos pela região onde atuam, pelo grupo criminoso do qual fazem parte, entre outros critérios, de modo a facilitar a identificação de ações criminosas (FRANÇA, 2012, p. 72).

Assim, a apresentação delas à pessoa da qual se pretende extrair o reconhecimento pode representar um reforço à já mencionada Teoria do Etiquetamento, uma vez que estudos demonstram que a memória e as crenças sociais atuam, junta e implicitamente, no modo de agir do indivíduo que, por sua vez, expressa tais preconcepções de forma involuntária (SCHACTER et al., 2001, p. 139).

Erving Goffman (1963, p. 47) assevera que, em determinadas situações, o status social de um indivíduo pode ser utilizado como fonte de informações acerca de sua própria identidade, próximo ao que, no Brasil, chamamos de "me diga com quem tu andas que eu te direi quem tu és". Assim, colocar um portfólio de "fichados" em frente à vítima tem o condão de influenciar no reconhecimento e de reforçar o estigma perante aqueles indivíduos com histórico de desvio.

Goffman (1963, p. 19) ainda apresenta o conceito de estigma como sendo um desacordo entre a identidade real (características que o indivíduo atribui a si mesmo) e a identidade virtual (imagem construída por outro sujeito). Importa destacar, no entanto, que ser etiquetado como desviante influencia não apenas na imagem do indivíduo em relação à sociedade, mas também na autoimagem, "pois o rótulo pode produzir uma 'profecia autorrealizadora'” (ÁVILA, 2013, p. 190).

Em razão do estigma que certas características e condições impõem ao indivíduo, o Supremo Tribunal Federal editou a Súmula Vinculante n. 11, a qual determina que a utilização de algemas só é lícita em casos excepcionais, sob pena de responsabilização da autoridade. No mesmo 
sentido, encontra-se o Decreto n. 8.858/2016, o qual regulamentou o art. 199 da Lei de Execução Penal, no tocante ao uso de algemas. Além de garantir o princípio da presunção de inocência, a limitação ao uso de algemas tem o condão de evitar o reconhecimento falho: se o suspeito é colocado algemado diante da vítima, há uma maior probabilidade de falso reconhecimento do que se ele for apresentado em uma sala e trajando roupas neutras (CECCONELLO; STEIN, 2020, p. 176).

Nesse problema também recai a abordagem policial. Para Martini (2007, p. 46), as forças policiais abordarão com mais facilidade as pessoas que se enquadram no estereótipo de potencial criminoso, estabelecido pelo senso comum, qual seja, negros, mendigos, homossexuais, profissionais do sexo "e, fundamentalmente, os despossuídos".

Ressalta-se que não é só a polícia que integra esse quadro. A mídia também toma parte nesse processo. O discurso midiático se legitima na sociedade ao criar uma distinção entre o "nós" e os "criminosos", uma linha imaginária entre as pessoas "boas" e as "más" (DIAS et al, 2013, p. 393), ou, até mesmo, entre os "cidadãos" e os "desviantes".

Esse abismo social representa um campo fácil para internalizar a publicidade midiática de um "eles inimigo", composto por pobres, imigrantes e adolescentes de bairros precários (ZAFFARONI, 2013, p. 109). A justiça penal, e sua maior severidade com criminosos negros, expressa a desigualdade de direitos que compromete o funcionamento e a consolidação da democracia na sociedade brasileira (MONTEIRO; CARDOSO, 2013, p. 107).

Embora não tratem de reconhecimentos pessoais, duas pesquisas fornecem interessantes exemplos do funcionamento do viés social. Na primeira, foi mostrada a uma testemunha uma imagem, com dois homens - um branco e outro negro - em uma discussão acalorada. O homem branco estava segurando uma lâmina. Quando solicitadas a recordar a imagem, um percentual significativo das testemunhas afirmou que a lâmina estava na mão do homem negro. O estudo provê elementos que nos indicam que a maneira como vemos e percebemos determinado evento depende de nossas crenças, formadas muito antes do fato (GROSS, 1999, p. 315).

Já na segunda pesquisa foram mostradas quatro histórias, todas com uma foto de um mesmo homem afro-americano. As histórias eram 
sobre (1) um professor universitário; (2) um jogador de basquete; (3) um crime não violento; (4) um crime violento. Após ver as fotos e ler as histórias, foi pedido aos participantes que reconstruíssem a foto do homem de cada história, escolhendo, dentre as opções, as características faciais. As histórias envolvendo crimes, principalmente a do crime violento, foram as que obtiveram mais características faciais "tipicamente" afro-americanas (MOURER, 2008, p. 56). Por essa razão, Thompson (2008, p. 1493) assevera que, depender da prova testemunhal para atingir a condenação, muitas vezes, envolve um elemento de discriminação racial.

Para Goffman (1963, p. 139), o estigma daqueles com "ficha suja", de determinadas religiões, raças e grupos étnicos, pode funcionar como uma forma de controle social, ao remover essas minorias de vários campos de competição e ao diminuir o campo de atuação da justiça criminal.

Nessa toada, um estudo, intitulado Hidden deviance and the Labelling Approach: the case for drinking and driving, concluiu que a questão étnico-racial é um fator determinante para a condenação nos Estados Unidos, independentemente do grau do desvio (reiteração/seriedade ou status socioeconômico). Em outras palavras, negros e latino-americanos têm mais chances de condenação, pouco influindo, para isso, a gravidade do desvio praticado (MARSHALL; PURDY, 1972, p. 550).

Exemplo disso é que, nos Estados Unidos, as prisões, que representam o $3^{\circ}$ maior empregador, têm como "clientes naturais" os negros, os latinos, os com baixa renda familiar e os condenados por crimes, em sua maioria, de drogas e contra o patrimônio. Situação semelhante ao que ocorre no Brasil (MONTEIRO; CARDOSO, 2013, p. 104).

Esses dados reforçam o defendido pela Teoria do Etiquetamento. Um dos critérios para a reação estatal é o reflexo da realidade social e do antagonismo das classes dominantes em relação aos indivíduos marginalizados e etiquetados como delinquentes (MAZONI; FACHIN, 2012, p. 8). Assim, o sistema penal não tem como função combater o crime em sociedade, mas atribuir rótulos de delinquentes àqueles indivíduos já considerados marginalizados.

Considerando toda a problemática envolvendo o reconhecimento pessoal, existem propostas legislativas que visam à melhor redação e regulamentação do art. 226 do Código de Processo Penal. O Projeto de Lei 
n. 3.300, de $2019^{17}$, prevê a necessidade de perfilar cinco indivíduos com características semelhantes às do acusado, além de estabelecer a necessidade de que a autoridade informe à pessoa que fará o reconhecimento de que o suspeito pode não estar incluído entre as pessoas ou fotografias apresentadas. Somado a isso, o PL ainda acrescenta que a autoridade responsável pela condução do reconhecimento não poderá influenciar no ato. Percebe-se, assim, o interesse em adequar a legislação processual penal aos estudos sobre falsas memórias e falibilidade do testemunho.

É possível depreender, de todo o exposto, que os depoimentos testemunhais são considerados de grande importância para a resolução de casos. Por outro lado, a maioria das práticas adotadas no procedimento de coleta de depoimentos e de reconhecimentos pessoais é passível de produzir evidências potencialmente distorcidas ou imprecisas, as quais serão utilizadas pelo Judiciário para condenar ou absolver alguém (STEIN; ÁVILA, 2018, p. 48).

Aliado a essa deficiência técnica, está o inconsciente coletivo acerca do etiquetamento daqueles considerados "marginalizados". Preconceitos e estigmas exercem forte influência no momento do reconhecimento pessoal e tendem a ser potencializados quando não observados os procedimentos adequados, o que resulta em verdadeira afronta ao in dubio pro reo, uma vez que serão mais facilmente identificados aqueles que "têm cara de bandido". A atual legislação processual penal, embora já preveja critérios para o reconhecimento, é insuficiente diante de todos os fatores que influenciam na qualidade do testemunho. Assim, aplicar a literatura estrangeira e nacional sobre a matéria ao processo legislativo proporcionaria uma legislação processual penal atualizada e adequada aos ditames do Estado Democrático de Direito.

\section{Considerações Finais}

De todo o exposto no presente trabalho, é possível perceber a importância da aplicação dos requisitos do art. 226 do Código de Processo

17 Disponível em: <https://www25.senado.leg.br/web/atividade/materias/-/ materia/137160>. Acesso em: 12 maio 2020. 
Penal como meio de assegurar as garantias constitucionais e evitar decisões que violam o in dubio pro reo e outros princípios igualmente importantes na efetivação do devido processo legal.

A prova testemunhal, da qual se destacam os reconhecimentos pessoais e fotográficos, sofre influência de variados fatores, que devem ser levados em consideração no momento de admissibilidade e valoração da prova.

Estudos indicam a ocorrência de múltiplos fatores responsáveis pela deturpação da memória e do reconhecimento. Cita-se, a título de exemplo, as falsas memórias, o reconhecimento cross-racial, o stress no momento do delito, o decurso de tempo entre o fato e o reconhecimento. A própria condução inadequada do reconhecimento pode sugestionar a memória da vítima e levá-la a indicar a pessoa errada como responsável pelo delito investigado.

Ademais, os preconceitos sociais são fatores determinantes no momento de etiquetamento do desvio e do desviante. Desse modo, cabe ao sistema de justiça a missão de, considerando as preconcepções sociais, descobrir meios de evitar o reforço à seletividade do sistema, o qual tem como "clientela" indivíduos negros, jovens e pertencentes às classes menos favorecidas.

Nesse passo, cumpre frisar que o regramento brasileiro atual, embora preveja mecanismos que, ao serem seguidos, diminuem a falibilidade do testemunho, ainda é incipiente quando confrontado com a vasta pesquisa nacional e estrangeira sobre o assunto. Assim, alterações legislativas, como a pretendida pelo PL n. 3300, de 2019, seriam capazes de aumentar a confiança na prova testemunhal e conferir-lhe validade.

Verifica-se, no entanto, que, não obstante a larga gama de estudos que versam sobre a matéria concordarem acerca da importância de se respeitar critérios adequados para o reconhecimento, a jurisprudência dominante no Brasil caminha na contramão das pesquisas, no âmbito da psicologia judiciária, ao aceitar os incisos do art. 226 do Código de Processo Penal como meras recomendações.

Nos Estados Unidos, embora não haja uniformidade relativa ao tratamento da matéria, as cortes vêm, cada vez mais, relativizando a prova testemunhal e exigindo determinados procedimentos no momento da coleta do testemunho, com o objetivo de diminuir a falibilidade e lhe conferir maior segurança. 
Assim, é possível concluir que as práticas costumeiras, a necessidade de celeridade processual e a vontade de resolver casos em nome da tutela jurisdicional não devem sobrepujar a atenção aos princípios norteadores do processo penal. A busca pela verdade real reside na utilização dos meios adequados para a efetivação do direito não apenas da vítima, como também do sujeito que se encontra no polo passivo da ação penal.

\section{REFERÊNCIAS}

ÁVILA, Gustavo Noronha de. Falsas memórias e sistema penal: a prova testemunhal em xeque. Rio de Janeiro: Editora Lumen Juris, 2013.

BARATTA, Alessandro. Princípios do Direito Penal Mínimo: para uma teoria dos direitos humanos como objeto e limite da lei penal. Tradução Francisco Bissoli Filho, 2003. Doctrina Penal, Argentina, ano 10, n. 87, p. 623-650, 1987.

BECKER, Howard S. Outsiders: studies in the sociology of deviance. New York: The Free Press, 1997.

BENSON, Christopher. The problem with eyewitness identification. Disponível em: <http://www.chicagoreporter.com/problem-eyewitness-identification/>. Acesso em: nov. 2019.

BESSNER, Ronda. Eyewitness identification in Canada. Criminal Law Quarterly, Canada, v. 25, p. 313-347, 1982-1983.

BRIGHAM, John C. The applications of eyewitness identification research to the courtroom. Journal of Community Psychology, v. 14, n. 3, p. 241-252, 1986. https:// doi.org/10.1002/1520-6629(198607)14:3<241::aid-jcop2290140303>3.0.co;2-5

BROWN, Rebecca; SALOOM, Stephen. The imperative of eyewitness identification reform and the role of police leadership. University of Baltimore Law Review, Baltimore, v. 42, p. 535-560, 2013.

CALIFORNIA INNOCENCE PROJECT. Eyewitness identification. Disponível em: $<$ https://californiainnocenceproject.org/issues-we-face/eyewitness-identification/>. Acesso em: nov. 2019.

CECCONELLO, William Weber; AVILA, Gustavo Noronha de; STEIN, Lilian Milnitsky. A (ir)repetibilidade da prova penal dependente da memória: uma discussão com base na psicologia do testemunho. Revista Brasileira de Políticas Públicas, Brasília, v. 8, n. 2, p. 1057-1073, 2018. https://doi.org/10.5102/rbpp.v8i2.5312 
CECCONELLO, William Weber; STEIN, Lilian Milnitsky. Prevenindo injustiças: como a psicologia do testemunho pode ajudar a compreender e prevenir o falso reconhecimento de suspeitos. Avances em Psicología Latinoamericana, Bogotá, v. 38, n. 1, p. 172-188, 2020. http://dx.doi.org/10.12804/revistas.urosario.edu. co/apl/a.6471

CLARK, Steven E. Blackstone and the balance of eyewitness identification evidence. Albany Law Review, Albany, v. 74, n. 3, p. 1105-1156, 2010.

CONWAY, Sara. A new era of eyewitness identification law: putting eyewitness testimony on trial. New England Law Review, Boston, v. 50, p. 81-118, 2015.

DAMÁSIO, António. O erro de Descartes: emoção, razão e o cérebro humano. São Paulo: Editora Companhia das Letras, 2012.

DIAS, Fábio Freitas; DIAS, Felipe da Veiga; MENDONÇA, Tábata Cassenote. Criminologia mediática e a seletividade do sistema penal. In: Anais do $2^{o}$ Congresso Internacional de Direito e Contemporaneidade: mídias e direitos da sociedade em rede, 2013. Disponível em: <http://coral.ufsm.br/congressodireito/anais/2013/3-7. pdf>. Acesso em: nov. 2019.

DIVAN, Gabriel Antinolfi. Editorial dossiê "Criminologia e Processo Penal”: O processo penal das misérias. Revista Brasileira de Ciências Criminais, São Paulo, ano 25, n. 128, p. 17-25, fev. 2017.

DOTSON, Jared T. The linchpin of identification evidence: the unreliability of eyewitnesses and the need for reform in West Virginia. West Virginia Law Review, Morgantown, v. 117, p. 775-829, 2014.

FRANÇA, Rafael Francisco. Meios de obtenção de prova na fase preliminar criminal: considerações sobre reconhecimento pessoal no Brasil e na legislação comparada. Revista Brasileira de Ciências Policiais, Brasília, v. 3, n. 2, p. 55-90, jul./ dez. 2012. https://doi.org/10.31412/rbcp.v3i2.58

GEE, Harvey. Cross-racial eyewitness identification, jury instructions and justice. Rutgers Race \& Law Review, Newark, v. 11, p. 70-118, 2009.

GESU, Cristina Di. Prova penal e falsas memórias. 2 ed. amp. e rev. Porto Alegre: Livraria do Advogado Editora, 2014.

GETZ, Dana. Who was the unabomber sketch artist? 'Manhunt: Unabomber' claims there was more than one. Disponível em: <https://www.bustle.com/p/who-wasthe-unabomber-sketch-artist-manhunt-unabomber-claims-there-was-more-than -one-78167>. Acesso em: nov. 2019. 
GOFFMAN, Erving. Stigma: notes on the management of spoiled identity. Englewood Cliffs: Prentice Hall Inc., 1963.

GROSS, William David. The unfortunate faith: a solution to the unwarranted reliance upon eyewitness testimony. Texas Wesleyan Law Review, Fort Worth, v. 5, p. 307- 331, 1999.

HANDBERG, Roger B. Expert testimony on eyewitness identification: a new pair of glasses for the jury. American Criminal Law Review, Washington, DC, v. 32, p. 1013-1064, 1995.

HOBSON, Zoe J.; WILCOCK, Rachel. Eyewitness identification of multiple perpetrators. International Journal of Police Science \& Management, London, v. 13, n. 4, p. 286-296, 2011. https://doi.org/10.1350/ijps.2011.13.4.253

HUGENBERG, Kurt; YOUNG, Steven G.; BERNSTEIN, Michael J.; SACCO, Donald F. The categorization-individuation model: an integrative account of the other race recognition deficit. Psychological Review, Miami, v. 117, p. 1168-1187, 2010. https://doi.org/10.1037/a0020463

INFOPEN. Levantamento nacional de informações penitenciárias. Brasília, 2019.

LEVERICK, Fiona. Jury instructions on eyewitness identification evidence: a re-Evaluation. Creighton Law Review, Omaha, v. 49, p. 555-588, 2016.

LIMA, Renato Brasileiro de. Manual de processo penal. Volume único. 4. ed. rev, ampl. e atual. Salvador: Ed. JusPodivm, 2016.

LOFTUS, Elizabeth F. Unconscious transference in eyewitness identification. Law and Psychology Review, Tuscaloosa, v. 2, p. 93-98, 1976.

LOPES JR., Aury; GESU, Cristina Carla Di. Falsas memórias e prova testemunhal no processo penal: em busca da redução de danos. Revista de Estudos Criminais, Porto Alegre, v. 7, n. 25, p. 59-69, 2007.

LOPES JR., Aury. Direito processual penal. 11. ed. São Paulo: Saraiva, 2014.

MALPASS, Roy S.; DEVINE, Patricia G. Guided memory in eyewitness identification. Journal of Applied Psychology, Plattsburgh, v. 66, n. 3, p. 343-350, 1981. https://doi.org/10.1037/0021-9010.66.3.343

MARSHALL, Harvey; PURDY, Ross. Hidden deviance and the labelling approach: the case for drinking and driving. Oxford University Press, Oxford, v. 19, n. 4, p. 541-553, 1972. https://doi.org/10.1525/sp.1972.19.4.03a00100 
MARTINI, Márcia. A seletividade punitiva como instrumento de controle das classes perigosas. MPMG Jurídico, Minas Gerais, ano III, n. 11, p. 45-47, out./nov. 2007.

MAYER, Connie. Due process challenges to eyewitness identification based on pretrial photographic arrays. Pace Law Review, New York, v. 13, n. 3, p. 815-861, 1994.

MAZONI, Ana Paula de Oliveira; FACHIN, Melina Girardi. A teoria do etiquetamento do sistema penal e os crimes contra a ordem econômica: uma análise dos crimes de colarinho branco. Revista de Direito Público, Londrina, v. 7. n. 1, p. 3-18, jan./abr. 2012. https://doi.org/10.5433/1980-511.2012v7n1p3

MELLIM FILHO, Oscar. Criminalização e seleção no sistema judiciário penal. Tese de Doutorado em Ciências Sociais - Pontifícia Universidade Católica de São Paulo, São Paulo, 2009.

MONTEIRO, Felipe Mattos; CARDOSO, Gabriela Ribeiro. A seletividade do sistema prisional brasileiro e o perfil da população carcerária. Civitas, Porto Alegre, v. 13, n. 1, p. 93-117, 2013. https://doi.org/10.15448/1984-7289.2013.1.12592

MOREIRA, Reinaldo Daniel. Notas sobre a seletividade do sistema penal. Revista Eletrônica da Faculdade Metodista Granberry, Juiz de Fora, v. 8, p. 1-16, 2010.

MOURER, Sarah Anne. Reforming eyewitness identification procedures under the fourth amendment. Duke Journal of Constitutional Law \& Public Policy, Durham, v. 3, p. 49-90, 2008.

NAUDE, Bobby. Ensuring Procedurally Fair Identification Parades in South Africa. South African Journal of Criminal Justice, Cape Town, v. 28, p. 188-203, 2015.

NORTON, Jerry E. recent appellate court decisions on eyewitness identification. Public Interest Law Reporter, Chicago, v. 11, p. 1-43, 2006.

NUCCI, Guilherme de Souza. Manual de processo penal e execução penal. 12. ed. rev., atual. e ampl. Rio de Janeiro: Forense, 2015.

RABNER, Stuart. Evaluating eyewitness identification evidence in the $21^{\text {st }}$ century. New York University Law Review, New York, v. 87, n. 5, p. 1249-1272, 2012.

ROBERTS, Andrew. Eyewitness identification: scene of crime confrontations The need for a more cautious approach. The Journal of Criminal Law, Cambridge, v. 63, n. 3, p. 251-262, 1999. https://doi.org/10.1177/002201839906300305

ROSE, Chris; BECK, Victoria. Eyewitness accounts: false facts, false memories and false identification. Journal of Crime and Justice, Oshkosh, v. 39, n. 2, p. 243-263, 2016. https://doi.org/10.1080/0735648x.2014.940999 
SCHACTER, Daniel L.; SCARRY, Elaine; MATHER, Mara. Memory, brain and belief. The American Journal of Psychology, Chicago, v. 114, n. 3, p. 473. https:// doi.org/10.2307/1423692

SHEEHAN, Christian. Making the jurors the experts: the case for eyewitness identification jury instructions. Boston College Law Review, Newton Centre, v. 52, p. 651-693, 2011.

SMALARZ, Laura; WELLS, Gary L. Eyewitness-identification evidence: scientific advances and the new burden on trial judges. Court Review, Williamsburg, v. 48, n. 1-2, p. 14-21, 2012.

STEBLAY, Nancy K. Scientific advances in eyewitness identification evidence. William Mitchell Law Review, Saint Paul, v. 41, n. 3, p. 1090-1128, 2015.

STEIN, Lilian Milnitsky. Falsas memórias: fundamentos científicos e suas aplicações clínicas e jurídicas. Porto Alegre: Artmed, 2010.

STEIN, Lilian Milnitsky; ÁVILA, Gustavo Noronha de. Entrevistas forenses e reconhecimento pessoal nos processos de criminalização: um diagnóstico brasileiro. Brasília: IPEA. Boletim de Análise Político-Institucional, n. 17, p. 45-51, 2018.

THOMPSON, Sandra Guerra. Beyond a reasonable doubt - Reconsidering uncorroborated eyewitness identification testimony. University of California, Davis, v. 41, p. 1487-1545, 2008.

TORTORA, Jason. Reconsidering the standards of admission for prior bad acts evidence in light of research on false memories and witness preparation. Fordham Urban Law Journal, New York, v. 40, p. 1493-1537, 2013.

TRENARY, Amy D. State v. Henderson: A model for admitting eyewitness identification testimony. The University of Colorado Law Review, Boulder, v. 84, n. 4, p. 1257-1303, 2013.

VALENTINE, Tim; MESOUT, Jan. Eyewitness identification under stress in the London dungeon. Applied Cognitive Psychology, v. 23, n. 2, p. 151-161, 2009. https://doi.org/10.1002/acp.1463

WALSH, Dana. The dangers of eyewitness identification: a call for greater state involvement to ensure fundamental fairness. Boston College Law Review, Newton Centre, Symposium Issue, v. 54, p. 1415-1453, 2013.

WELLS, Gary L.; SMALL, Mark; PENROD, Steven; MALPASS, Roy S.; FULERO, Solomon M.; BRIMACOMBE, C.A.E. Eyewitness identification procedures: 
recommendations for lineups and photospreads. Law and Human Behavior, Washington, DC, v. 22, n. 6, 1998. https://doi.org/10.1023/a:1025750605807

ZAFFARONI, Eugenio Raul. A questão criminal. Tradução Sérgio Lamarão. 1. ed. Rio de Janeiro: Revan, 2013.

\section{Informações adicionais e declarações dos autores (integridade científica)}

Agradecimentos (acknowledgement): Agradeço aos meus professores da Universidade de Brasília e do Instituto Brasiliense de Direito Público, sem os quais eu não teria condições críticas e teóricas de iniciar uma discussão sobre o tema, seja por falta de embasamento ou até mesmo por ausência de material para pesquisa.

Declaração de conflito de interesses (conflict of interest declaration): a autora confirma que não há conflitos de interesse na realização das pesquisas expostas e na redação deste artigo.

Declaração de autoria e especificação das contribuições (declaration of authorship): todas e somente as pessoas que atendem aos requisitos de autoria deste artigo estão listadas como autores; todos os coautores se responsabilizam integralmente por este trabalho em sua totalidade.

Declaração de ineditismo e originalidade (declaration of originality): a autora assegura que o texto aqui publicado não foi divulgado anteriormente em outro meio e que futura republicação somente se realizará com a indicação expressa da referência desta publicação original; também atesta que não há plágio de terceiros ou autoplágio. 
Dados do processo editorial

(http://www.ibraspp.com.br/revista/index.php/RBDPP/about/editorialPolicies)

- Recebido em: 27/01/2020

- Controle preliminar e verificação de plágio: 04/03/2020

- Avaliação 1: 19/03/2020

- Avaliação 2: 24/03/2020

- Avaliação 3: 25/03/2020

- Decisão editorial preliminar e deslocamento V6N3: 28/04/2020

- Retorno rodada de correções: 22/05/2020

- Decisão editorial final: 08/06/2020

\section{Equipe editorial envolvida}

- Editor-chefe: 1 (VGV)

- Editor-assistente: 1 (GNA)

- Revisores: 3

\section{COMO CITAR ESTE ARTIGO:}

MAGALHÃES, Marina Trindade. O reconhecimento pessoal e a psicologia judiciária: falibilidade do testemunho como reforço do etiquetamento e violação ao in dubio pro reo. Revista Brasileira de Direito Processual Penal, Porto Alegre, vol. 6, n. 3, p. 1699-1731, set./dez. 2020. https://doi.org/10.22197/rbdpp.v6i3.339

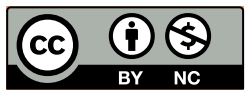

Esta obra está licenciada com uma Licença Creative Commons Atribuição-NãoComercial 4.0 Internacional. 